\title{
RELEASE OF ${ }^{125}$ I-rhBMP-2 FROM FOAMED POLY-(D,L)-LACTIDE
}

\author{
Sänger $\mathrm{T}^{1}$, Laub $\mathrm{M}^{2}$, Jennissen H.P ${ }^{1}$ \\ ${ }^{1}$ Institut für Physiologische Chemie, Universitätsklinikum Essen, Hufelandstr. 55, D-45122 Essen, Germany \\ ${ }^{2}$ Morphoplant GmbH, Universitätsstr. 136, D-44799 Bochum, Germany
}

thorsten.saenger@uk-essen.de; hp.jennissen@uni-due.de

\begin{abstract}
:
Composite tablets of human recombinant bone morphogenetic protein 2 (rhBMP-2) and poly-(D,L)lactide (PDLLA) (1-2 mg rhBMP-2/g PDLLA) were prepared by foaming of PDLLA with supercritical $\mathrm{CO}_{2}$. Release kinetics of rhBMP-2 were measured by a continuous flow and a batch dilution method at $22{ }^{\circ} \mathrm{C}$ and $50{ }^{\circ} \mathrm{C}$ respectively. In both cases a two-phase first-order release was found. Release half-lives of the sustained release phases $(87-90 \%$ of total) decreased significantly from 348 days at $22^{\circ} \mathrm{C}$ to 86 days at $55^{\circ} \mathrm{C}$ i.e. by a factor of 4 indicating a coupling with PDLLA hydrolysis. The released rhBMP-2 was biologically active.
\end{abstract}

Keywords: polylactide, foaming with supercritical $\mathrm{CO}_{2}$, rhBMP-2, release kinetics, rate-constants

\section{Introduction}

In the preparation of bioactive implant materials either by the adsorption or encapsulation of protein growth factors a bioadapted drug delivery is one of the major objectives. Release kinetics of a substance from a polymer substrate can be described by the following equation (see ref. [1]):

$$
-\frac{d[\mathbb{P} \cdot P L A]}{d t}=k_{1}[\mathbb{P} \cdot P L A]-k_{2}[\mathbb{P}][P L A]
$$

where $k_{l}$ and $k_{2}$ are the rate constants of dissociation and association (i.e. readsorption) respectively. $[\mathbb{P}],[P L A)]$ and $[\mathbb{P} \bullet P L A]$ denote the concentration of protein, polylactic acid and the protein-polylactic acid complex respectively. Under the condition that the system is far from equilibrium, the second term (readsorption) becomes zero and eq. 1 reduces to a first order reaction, which on integration yields the exponential equation:

$$
[\mathbb{P} \cdot P L A]=\mathrm{C} \mathrm{e}^{-\mathrm{kt}}
$$

where $\mathrm{C}=[\mathbb{P} \bullet P L A]_{0}$ i.e. the initial concentration of the protein-polylactic acid complex at time zero. First-order kinetics have also been shown for the degradation of the polymers poly(lactic-co-glycolic acid) (PLGA) [2] and PLA [3]. If the protein is released into a reservoir within the polymer and its diffusion to the bulk is restricted by pores, then linear zero-order kinetics are observed [4]. The major techniques for eliminating readsorption are dilution [1,5] and release under continuous flow conditions as will be shown below. As a model system
${ }^{125}$ I-rhBMP-2 incorporated into PDLLA tablets by foaming with supercritical $\mathrm{CO}_{2}\left(\mathrm{scCO}_{2}\right)$ [6] will be employed.

\section{Methods}

Self-prepared rhBMP-2 [7,8] (activity equivalent: $\mathrm{K}_{0.5} \sim 5$ $20 \mathrm{nM}[8,9])$ was employed and labelled with ${ }^{125} \mathrm{I}-$ rhBMP-2 [7]. $1 \mathrm{~g}$ defined PDLLA granules with $\mathrm{CaCO}_{3}$ was suspended in $1.6 \mathrm{ml}{ }^{125} \mathrm{I}-\mathrm{BMP}-2$ solution and intensely homogenized [6]. During the mixing procedure a slurry formed which was lyophilized to a powder and fluidized in teflon molds ( $10 \times 5 \times 2 \mathrm{~mm}$ openings) for 16 $\mathrm{h}$ at $45^{\circ} \mathrm{C}$ and $100 \mathrm{bar}$, depressurization 1-2 min, yielding composite tablets $10 \times 5 \times 2 \mathrm{~mm}$, weight: $\sim 38 \mathrm{mg}$, vol. $\sim 0.106 \mathrm{~cm}^{3}$.

In method 1 (continuous flow) the tablets were placed in a flow cell (Fig. 1) at room temperature $\left(\sim 22^{\circ} \mathrm{C}\right)$. To wash out released protein, cells were perfused with PBS $(\mathrm{pH}$ 7.4) at a flow-rate of ca. $10 \mathrm{~mL} / \mathrm{h}$ by a multiple channel peristaltic pump (205 S, Fa. Watson-Marlow, Willmington, USA) for 40 days. At specified times, the flow cell with the tablet, was measured in a $\gamma$-counter. After the experiments the empty flow cells were corrected for nonspecifically adsorbed ${ }^{125} \mathrm{I}-\mathrm{rhBMP}-2$ during release. Nonspecifically retained rhBMP-2 comprised ca $6-7 \%$ of the released ${ }^{125} \mathrm{I}$-rhBMP-2. In method 2 (batch dilution) ${ }^{125} \mathrm{I}$ rhBMP-2 was released from the ${ }^{125} \mathrm{I}$-rhBMP-2/PDLLA tablets into $1.5 \mathrm{~mL}$ PBS-buffer $(\mathrm{pH} 7.4)$ in vials on a in a heated shaker at $50{ }^{\circ} \mathrm{C}$ for 40 days. At the indicated times the tablets were washed two times with $1.5 \mathrm{~mL}$ fresh PBS, resuspended in $1.5 \mathrm{~mL}$ and counted in a $\gamma$-counter. Curves were fitted by the PC program Prism 4 for Windows [8]. Calculated half-lives were corrected for the spontaneous decay of ${ }^{125} \mathrm{I}\left(\mathrm{t}_{1 / 2}=60 \mathrm{~d}\right)$.

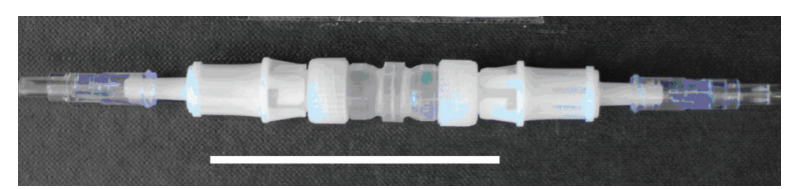

Fig.1: Flow cell in continuous flow method. The tablet was placed in the chamber (vol. $1.5 \mathrm{~mL}$ ). Scale: $4 \mathrm{~cm}$.

\section{Results}

Fig. 2 and Fig. 3 show the double exponential decay of ${ }^{125} \mathrm{I}-$ rhBMP-2 /PDLLA tablets at $22{ }^{\circ} \mathrm{C}$ and $50{ }^{\circ} \mathrm{C}$ respecttively. The derived rate constants are shown in Table 1 together with half-lives of the burst and the sustained release phases. The decay rate increases 4 -fold at $50{ }^{\circ} \mathrm{C}$. There was no indication of a significant readsorption. 


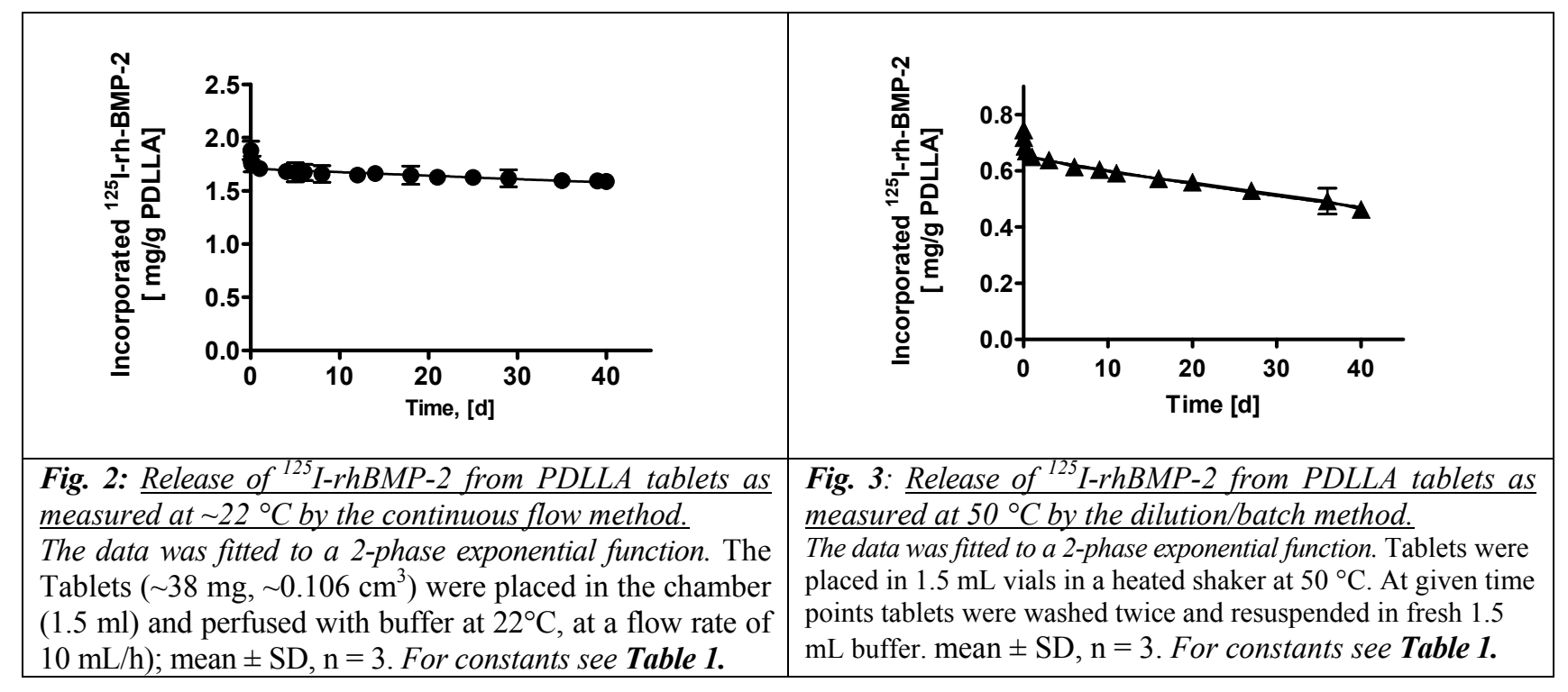

Table 1: Comparison of the calculated kinetic data of the releasing kinetics*.

\begin{tabular}{|c|c|c|c|c|c|c|c|c|c|}
\hline \multirow{2}{*}{$\begin{array}{l}\text { Temperature } \\
{ }^{\circ} \mathrm{C}\end{array}$} & \multirow{2}{*}{$\begin{array}{c}\text { incorporated } \\
{ }^{125} \text { I-rh-BMP-2 } \\
{[\text { mg/g PDLLA }]}\end{array}$} & \multicolumn{2}{|c|}{ Spans } & \multicolumn{2}{|c|}{\begin{tabular}{ll}
\multicolumn{2}{c}{ Rate-constants } \\
Burst phase $\quad$ Sustained rel. ph.
\end{tabular}} & \multicolumn{2}{|c|}{ Half-lives } & \multirow{2}{*}{$\mathrm{P}_{\text {runs }}$} & \multirow{2}{*}{$r^{2}$} \\
\hline & & Span a & Span b & $\mathrm{k}^{\mathrm{a}}{ }_{-1}\left[\mathrm{~s}^{-1}\right] \times 10^{5}$ & $\mathrm{k}_{-1}^{\mathrm{b}}\left[\mathrm{s}^{-1}\right] \times 10^{8}$ & $\mathrm{t}^{\mathrm{a}}{ }_{1 / 2}[\mathrm{~d}]$ & $\begin{array}{l}\mathrm{t}^{\mathrm{b}} \\
{[\mathrm{d}]}\end{array}$ & & \\
\hline$\sim 22$ & $1.880 \pm 0.086$ & 1.700 & 0.168 & $14.56 \pm 1.23$ & $2.3 \pm 0.0063$ & $\begin{array}{c}0.055 \pm \\
0.0046\end{array}$ & $\begin{array}{c}348 \pm \\
1.0\end{array}$ & 0.319 & 0.97 \\
\hline 50 & $0.745 \pm 0.014$ & 0.651 & 0.089 & $6.45 \pm 0.98$ & $9.3 \pm 0.279$ & $\begin{array}{c}0.124 \pm \\
0.019\end{array}$ & $\begin{array}{c}85.5 \pm \\
2.6\end{array}$ & 0.2086 & 0.99 \\
\hline
\end{tabular}

*The release of ${ }^{125}$ I-rh-BMP-2 can be fitted according the following equation : $y=$ Span $a \cdot e^{-k_{1} \cdot t}+$ Span $b \cdot e^{-k_{2} \cdot t}+$ Plateau $($ Plateau $=0)$. Results are stated as (mean \pm SEM, $n=3)$. The burst phase is marked as a, main phase as $b$. Spans $=$ Amount of released ${ }^{125}$ I-rh-BMP-2 for each phase: burst phase 10-13\%, main phase $87-90 \%$

\section{Discussion}

The experiments demonstrate first-order release kinetics of rhBMP-2 from foamed PDLLA tablets in agreement with PLA hydrolysis [3]. A temperature increase form $22^{\circ} \mathrm{C}$ to 50 ${ }^{\circ} \mathrm{C}$ increases the dissolution rate of ${ }^{125} \mathrm{I}$-rhBMP-2/PDLLA tablets (possibly by PDLLA hydrolysis) by a factor of 4 .

\section{Acknowledgement}

This work was supported by the Deutsche Forschungsgemeinschaft DFG Grant Je 84/15-1.

\section{Bibliography}

[1] Jennissen, H.P. \& Botzet, G. (1979) Kinetics of multivalent alkane-protein interactions on hydrophobic agaroses and implications for the multivalent effector-receptor model. Protides Biol. Fluids Proc. Colloq. 26, 657-660. (Peeters, H., Ed.), Pergamon Press, Oxford, New York.

[2] Zolnik, B.S. \& Burgess, D.J. (2007) Effect of acidic pH on PLGA microsphere degradation and release. J. Control Release, 122, 338-344.

[3] Lin, S.Y., Chen, K.S., Teng, H.H., \& Li, M.J. (2000) In vitro degradation and dissolution behaviours of microspheres prepared by three low molecular weight polyesters. $J$. Microencapsul., 17, 577-586.

[4] McGee, J.P., Davis, S.S., \& O'Hagan, D.t. (1995) Zero order release of protein from poly(D,L-lactide-co-glycolide) microparticles prepared using a modified phase separation technique. J. Control. Release, 34, 77-86.

[5] Jennissen, H.P. \& Botzet, G. (1979) Protein binding to twodimensional hydrophobic binding-site lattices: Adsorption hysteresis on immobilized butyl-residues. Int J Biol Macromol, 1, 171-179.

[6] Lange, M., Sänger, T., Chatzinikolaidou, M., Laub, M., \& Jennissen, H.P. (2009) rhBMP-2 Composite of Foamed Poly(D,L-) Lactide as Drug Delivery System for Bone Tissue Engineering. Abstr. Commun. No. 1560 in Proceedings of the 8th World Biomaterials Congress, Amsterdam, NL, May 28June 1, 2008. Vol. 1, pp. 151-151. Joost de Bruijn, Ed.; Curran Associates, Inc., Red Hook, NY 12571, USA; ISBN: 978-161567-080-2.

[7] Jennissen, H.P., Zumbrink, T., Chatzinikolaidou, M., \& Steppuhn, J. (1999) Biocoating of Implants with Mediator Molecules: Surface Enhancement of Metals by Treatment with Chromosulfuric Acid. Materialwiss. Werkstofftech. (Mater. Sci. Eng. Technol. ), 30, 838-845.

[8] Chatzinikolaidou, M., Lichtinger, T.K., Müller, R.T., \& Jennissen, H.P. (2010) Peri-implant reactivity and osteoinductive potential of immobilized rhBMP-2 on titanium carriers. Acta Biomater., 6, 4405-4421.

[9] Laub, M., Chatzinikolaidou, M., \& Jennissen, H.P. (2007) Aspects of BMP-2 Binding to Receptors and Collagen: Influence of Cell Senescence on Receptor Binding and Absence of High-Affinity Stoichiometric Binding to Collagen. Materialwiss. Werkstofftech. (Mat. Sci. Engineer. Technol.), 38, 1020-1026. 